\title{
EAD: TERRENO FÉRTIL PARA A EXPERIMENTAÇÃO METODOLÓGICA?
}

\author{
SÃO PAULO/SP MAIO/2018
}

\author{
ANGELO LUIZ CORTELAZZO - UNICAMP - alcortelazzo@gmail.com \\ DILERMANDO PIVA JUNIOR - FATEC-ITU - pivajr@gmail.com \\ MARIA RAFAELA JUNQUEIRA BRUNO RODRIGUES - FDF, FATEC-FRANCA/RIBEIRÃO PRETO - \\ mrjunque@gmail.com
}

Tipo: Investigação Científica (IC)

Natureza: Descrição de Projeto em Andamento

Categoria: Pesquisa e Avaliação

Setor Educacional: EDUCAÇÃO SUPERIOR

\begin{abstract}
RESUMO
O trabalho analisa, a partir da pesquisa de termos referenciais em trabalhos acadêmicos, a produção ligada às metodologias ativas de aprendizagem (MAA) na educação em geral e, em especial, em cursos a distância $(E a D)$. Os resultados mostram que há uma grande quantidade de trabalhos que se reportam a essas metodologias, mas que apenas 10\% deles explicitam seu desenvolvimento em cursos EaD. Além disso, mostram que em 2017 as metodologias mais abordadas foram a aprendizagem baseada em problemas (PBL), em projetos (PrBL), jogos (games), instrução pelos pares (peer instruction), sala-de-aula invertida (flipped classroom) e uso de portfolios. Também foi verificada a preponderância do PBL na área de saúde e, no Brasil, a grande importância dessa área nos estudos ligados a MAAs. Foi revelado, ainda, que os autores nem sempre especificam "metodologias ativas de aprendizagem" em seus termos referenciais, preferindo o uso direto da metodologia estudada, sem referência à sua classificação com relação à postura do aluno no processo.
\end{abstract}

Palavras-chave: Metodologias ativas de aprendizagem, produção acadêmica brasileira, ensino a distância. 


\section{Introdução}

A educação a distância (EaD), prevista como modalidade para o desenvolvimento de cursos formais na educação brasileira desde 1996 (BRASIL, 1996) tem tido, no ensino superior, um crescente aumento de matriculados e, com isso, crescente importância relativa para a formação superior no país. Dados do Censo da Educação Superior realizado pelo Instituto Nacional de Pesquisas Educacionais "Anísio Teixeira" - INEP referentes a 2016 (INEP, 2016), revelaram a existência de 1,5 milhões de alunos no ensino a distância, o que representa quase $20 \%$ do total de matrículas em cursos de graduação ofertados no Brasil.

Em 2017 foram listados onze periódicos nacionais que possuem a expressão "EaD" no título ou que são editados por grupos ou programas voltados para o ensino a distância (MATTAR, 2017), o que denota a importância crescente do tema. Destaque-se que há muitos outros periódicos que publicam artigos sobre EaD, especialmente aqueles que tratam de novas tecnologias aplicadas ao ensino ou informática na educação.

O protagonismo do estudante frente a sua aprendizagem é uma necessidade inerente ao desenvolvimento de um curso a distância uma vez que, de forma geral, ele tem uma maior liberdade temporal e espacial para a realização das atividades curriculares previstas. Entretanto, esse protagonismo não é automático e, segundo Moran (2015) 0 estímulo e a motivação à pesquisa são desafios constantes em $\mathrm{EaD}$, decorrente da falta de autonomia trazida pelos alunos que iniciam esses cursos. De todo o modo, um aluno matriculado em curso desenvolvido a distância deve, em geral, buscar ativamente as informações e conteúdos disponibilizados normalmente no ambiente virtual de aprendizagem (AVA). Por esse motivo, seria de se esperar que as chamadas metodologias ativas de aprendizagem estivessem presentes nesses cursos e se expressassem na produção de conhecimento novo e relatos de sua eficiência e uso para o processo de ensino-aprendizagem dos cursos superiores do país.

O presente trabalho buscou relacionar a produção de trabalhos que citam as metodologias ativas de aprendizagem e a forma como os cursos são desenvolvidos, focando nas relações existentes entre os termos utilizados, a educação brasileira e o ensino a distância de forma geral.

\section{Metodologia}

Para a estimativa da produção acadêmica referente a metodologias ativas de aprendizagem, foi estabelecido o período de 20 anos, a partir de 1998 e até 2017, com 
consulta no Google Acadêmico, eliminando-se citações e patentes. A pesquisa foi realizada com os seguintes termos: "active learning" com listagem de trabalhos em todos os idiomas; "metodologias ativas", "aprendizagens ativas" e "metodologias ativas de aprendizagem", pesquisados apenas em páginas de língua portuguesa, assumindo que a maioria dos trabalhos encontrados nas mesmas refere-se a produções brasileiras. Para o termo "metodologias ativas de aprendizagem" foram separados os trabalhos da área de saúde em relação aos demais. Os trabalhos do ano de 2017 foram classificados segundo a metodologia ativa de aprendizagem utilizada em seu desenvolvimento, a partir da leitura de seus resumos e de suas palavras-chave. Foram ainda contabilizados os trabalhos em que aparecem especificamente as principais metodologias de aprendizagem encontradas nesse ano de 2017.

\section{Resultados e Discussão}

Os termos "active learning" e "metodologias ativas" no período de 20 anos (1998 a 2017) foram encontrados milhares de vezes, especialmente em língua inglesa, com 29.900 publicações em 2017. Sites em língua portuguesa revelaram 1.670 artigos em 2017, ou seja, cerca de dezoito vezes menos (Figura 1).

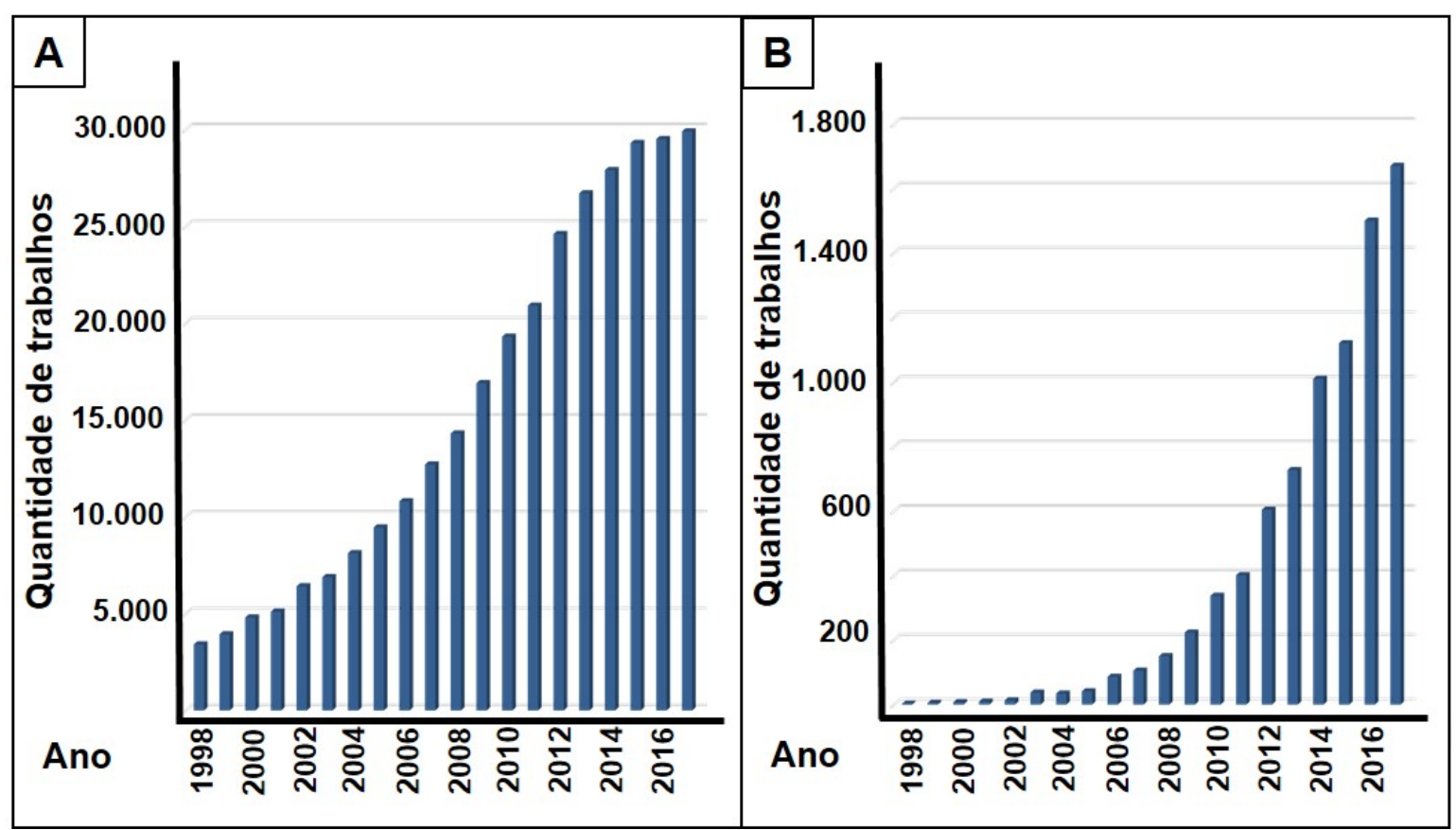

Figura 1. Quantidade de trabalhos com o termo "active learning" (A) ou "metodologias ativas" (B) no período de 1998 a 2017. (Fonte: Google acadêmico).

Nota-se que a produção de artigos em inglês ("active learning") apresenta uma curva sigmoide no período analisado, praticamente dobrando sua quantidade a cada 5 anos até 2012 e, no último quinquênio, teve um crescimento mais modesto, praticamente 
estabilizado nos três últimos anos (Figura 1A). A produção em língua portuguesa, que apresentou menos de 100 trabalhos/ano até 2006 apresentou crescimento expressivo e continuou em franca expansão em todo o período analisado (Figura 1B).

A pesquisa dos termos "aprendizagens ativas" ou "metodologias ativas de aprendizagem", apenas nas páginas em português do Google acadêmico, encontrou valores significativamente menores (Figura 2A). Nota-se que o termo "aprendizagens ativas" atingiu seu máximo com pouco mais de 150 trabalhos em 2014, decrescendo depois disso para 77 trabalhos em 2017. Em contrapartida, MAP continuou com crescimento acentuado, com valores superiores a 50 trabalhos a partir de 2010 e chegou a 317 no último ano analisado, com crescimento médio de $240 \%$ nos últimos 5 anos (Figura 2A).

Por tratar-se de metodologia ativa de aprendizagem, a aprendizagem baseada em problemas implantada em cursos da área de saúde no final do século passado assumiram uma importância significativa no Brasil (BERBEL, 1998) e, por esse motivo, foram quantificados os trabalhos encontrados no período analisado, a partir do termo "metodologias ativas de aprendizagem" e para cada ano, separados os resultados de estudos na área de saúde ou nas demais áreas (Figura 2B).

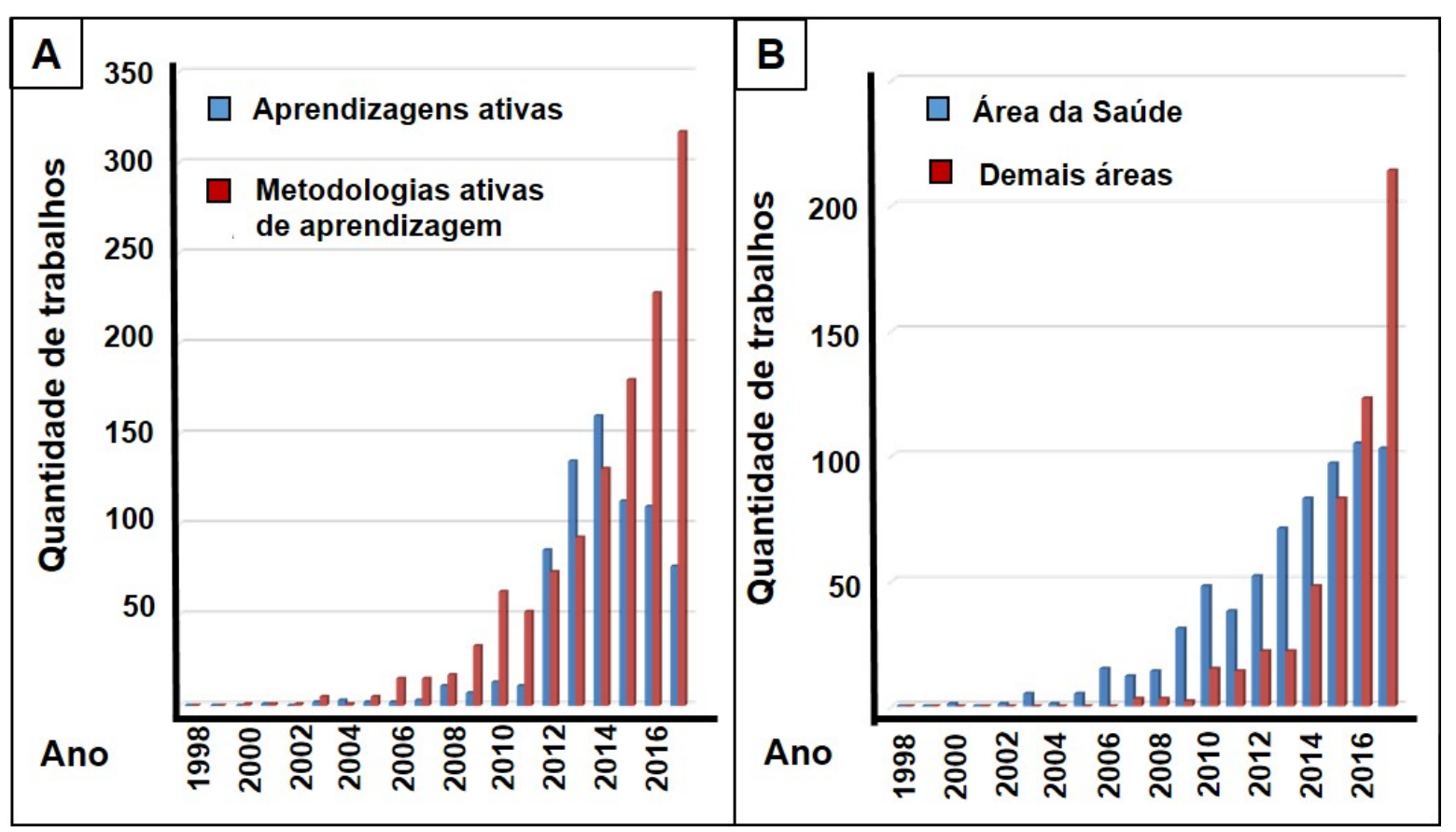

Figura 2. (A): Quantidade de trabalhos com os termos "aprendizagens ativas" ou “metodologias ativas de aprendizagem" encontrada no Google acadêmico no período de 1998 a 2017. (B): Trabalhos com o termo "metodologias ativas de aprendizagem" no mesmo período, comparando aqueles da área de saúde com as demais. (Fonte: Google acadêmico). 
Os resultados revelaram que, apesar da área de saúde representar a quase totalidade dos trabalhos na primeira década do século $\mathrm{XXI}$, as demais áreas foram gradativamente aumentando sua participação e em 2016 a ultrapassaram (105 trabalhos na área da saúde e 123 nas demais áreas). Esse aumento de produção das demais áreas foi reforçado significativamente em 2017, quando foi encontrada na área de saúde praticamente a mesma quantidade de trabalhos (103) e nas demais, praticamente 0 dobro, com 214 dos 317 trabalhos listados para esse termo (Figura 2).

A fim de qualificar os trabalhos encontrados com o termo "metodologias ativas de aprendizagem", foram analisados os resumos e palavras-chave dos 317 trabalhos encontrados no ano de 2017. Foram então discriminadas as seguintes metodologias ativas de aprendizagem abordadas e dispostas em ordem alfabética: a) aprendizagem baseada em problemas ou problem based learning (PBL); b) aprendizagem baseada em projetos ou project based learning ( $\mathrm{PrBL}$ ); c) aprendizagem baseada em times ou team based learning (TBL); d) (uso de) filmes ou movies (Filmes); e) instrução pelos pares ou peer instruction (PI); f) (uso de) jogos ou games (Jogos); g) (construção de) portfolios; $h$ ) (uso de) redes sociais (Redes); i) sala de aula invertida ou flipped classroom (FC); j) gerais, envolvendo estágios, trabalhos de conclusão de curso, iniciação científica, programa de iniciação a docência - PIBID; monitorias, oficinas, semanas pedagógicas, preceptorias na área da saúde, visitas técnicas (Geral); e k) trabalhos que não se encaixaram nos itens anteriores, compondo projetos pedagógicos de cursos, de instituições e outros temas como qualidade de ensino, avaliação etc. (NC) e que somaram 33 na área da saúde e 62 nas demais áreas não ultrapassando, em nenhum dos casos, $1 / 3$ do total de trabalhos encontrados. Todos os resultados foram colocados em gráfico apresentado na Figura 3.

É importante notar que os trabalhos relativos à aprendizagem baseada em problemas continuam numericamente maiores para os cursos da área de saúde, com 37 ocorrências contra 22 das demais áreas, mostrando que a metodologia continua preponderando para cursos de medicina, enfermagem, fisioterapia e outros.

Nos cursos das demais áreas destacaram-se os trabalhos classificados como "gerais", abordando temas e atividades curriculares diversas, seguidos de metodologia da aprendizagem baseada em projetos, em problemas, "games", "peer instruction" e sala de aula invertida (Figura 3). 


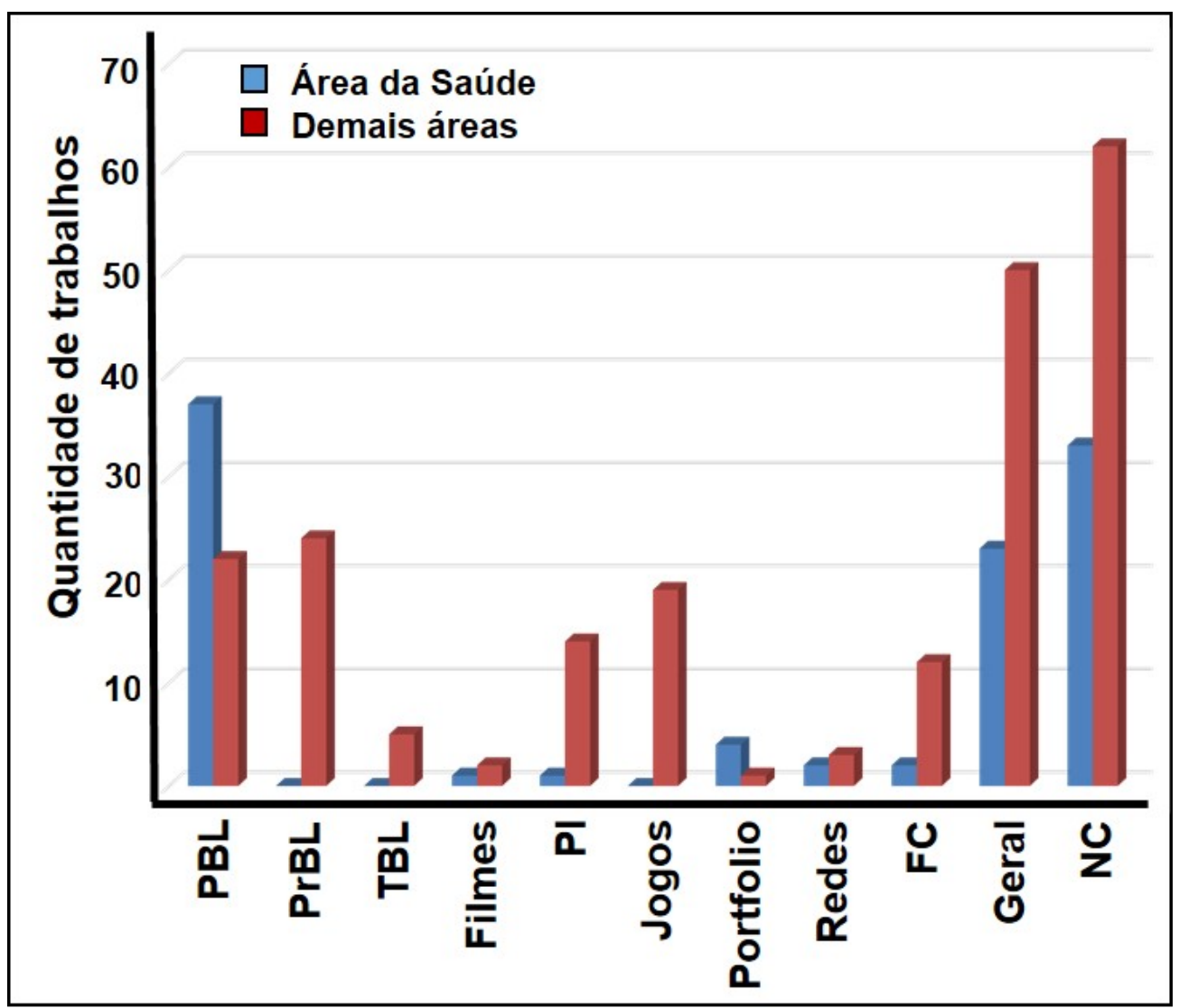

Figura 3. Quantidade de trabalhos classificados em função do tipo de metodologia ativa de aprendizagem. PBL - Problem based learning; PrBL - Project based learning; TBL - Team based learning; PI - Peer instruction; FC - Flipped classroom; Geral - trabalhos de natureza geral; NC - não classificados.

A situação retratada na Figura 3 mostra que quando descontamos os 95 trabalhos não classificados, obtemos 222 trabalhos que retratam alguma situação específica do uso de pelo menos uma metodologia ativa de aprendizagem. Destaque-se que em apenas 24 desses trabalhos (pouco mais de 10\%) houve referência explícita ao ensino a distância no resumo ou palavras-chave, valor que se eleva para $16 \%$ dos trabalhos quando não se computam os trabalhos da áreas da saúde, já que para estes, em sua maioria, se desenvolvem presencialmente. Um trabalho de revisão da literatura realizado por Fonseca e Mattar Neto (2017) num período de 10 anos (2006-2016) no Google Acadêmico com as expressões "metodologias ativas" e "cursos a distância" em qualquer lugar dos textos, teve um retorno inicial de 206 trabalhos no período, o que significa uma média de 20 trabalhos/ano, ou seja, valor que mostra a coerência daquele obtido no presente estudo.

As seis principais metodologias ativas encontradas no ano de 2017 foram pesquisadas no Google Acadêmico e os resultados obtidos encontram-se na Figura 4. Pode-se notar que a quantidade de trabalhos sobre aprendizagem baseada em problemas (PBL) 
permaneceu constante nos três últimos anos, o mesmo ocorrendo para jogos ("games/gamification"), "peer instruction" (PI) e "team based learning" (TBL) para artigos em inglês. Contrariamente, para páginas em português, apenas PBL permaneceu constante. Cumpre ressaltar que o termo "games" origina dezenas de milhares de trabalhos e, por esse motivo optou-se por utilizar "games in education" ou "gamification of learning", o que torna mais imprecisa a pesquisa para essa metodologia.

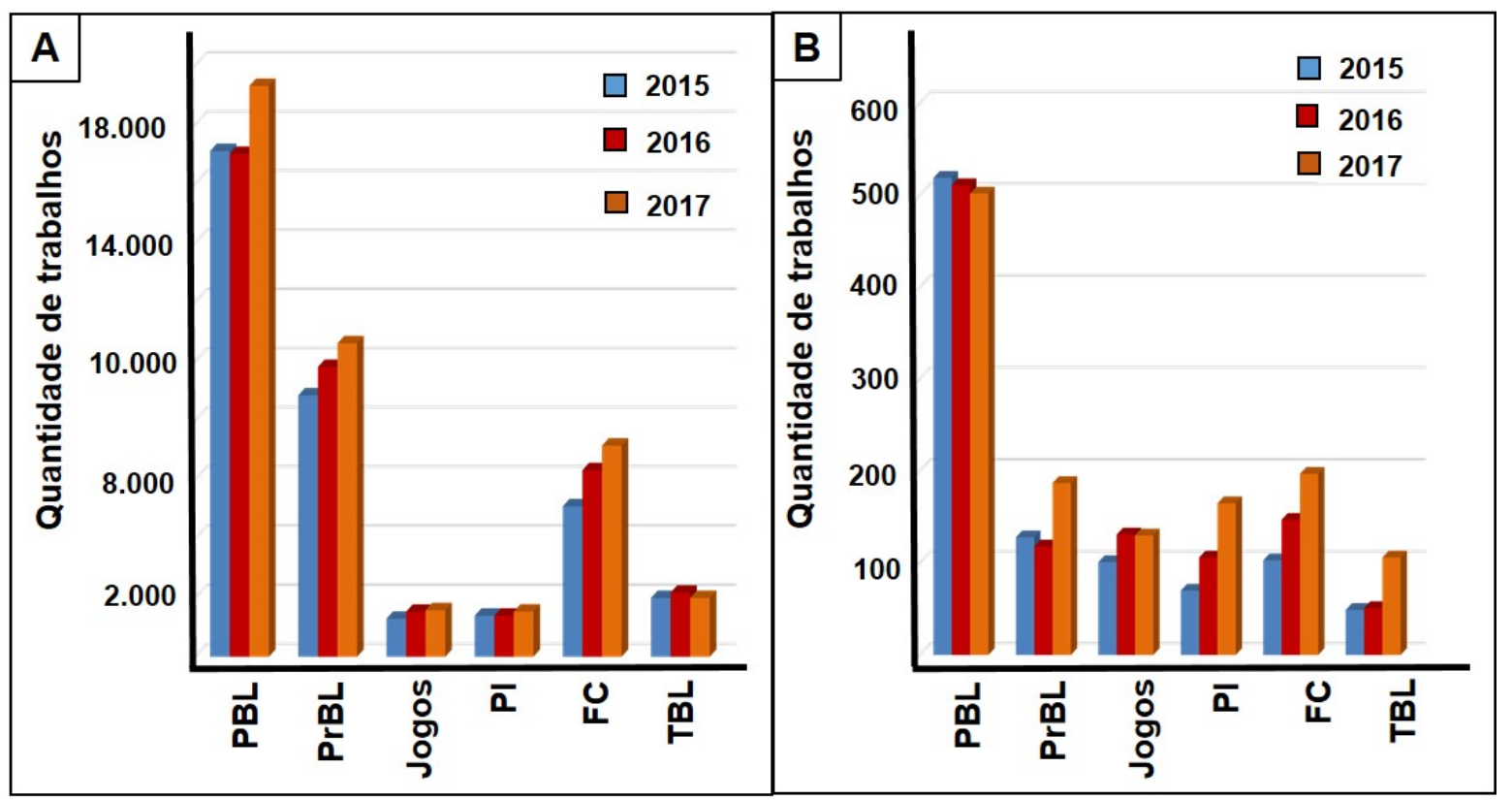

Figura 4. Seis metodologias ativas com maior número de trabalhos em 2017, encontradas em qualquer idioma no Google acadêmico $(A)$ ou apenas em língua portuguesa (B).

Os resultados mostram que a quantidade de trabalhos que utiliza uma dada metodologia, nem sempre utiliza o termo "metodologia ativa de aprendizagem" já que foram encontradas em 2017 apenas 317 ocorrências desse termo e a soma das ocorrências mostradas na Figura 4 é de 1.287 trabalhos.

Das onze publicações em que a expressão "EaD" aparece no título ou que são editadas por grupos ou programas voltados para o ensino a distância segundo Mattar (2017), dez delas apresentaram uma produção total de 226 trabalhos ao longo do ano de 2017 (a de ISSN 2237-2334 não tem produção nesse ano) o que também é um resultado bastante próximo daquele obtido neste trabalho. Dentre elas, 7 são classificadas com conceito "qualis C", e as três outras, uma em cada um dos conceitos B2, B4 e B5 da área de educação (CAPES, 2016). A área de educação da CAPES classifica cerca de 4.200 periódicos, dos quais $12 \%$ apresentam "qualis A', $57 \%$ são "qualis B" e $31 \%$ "qualis C" 
- que denota que as revistas citadas ainda apresentam uma qualificação inferior à média da área, o que pode estar associado à ligação dos periódicos qualificados à pósgraduação, ainda quase que totalmente constituída por programas presenciais.

Cabe destaque o fato de que as metodologias ativas normalmente estão associadas a uso intensivo de tecnologias de informação e comunicação (TICs). Entretanto, vários estudos demonstram que nem sempre isso é real e que é preciso desmistificar essa ideia. Segundo Rocha (2014) que trabalhou duas metodologias ativas de aprendizagem com 116 professores, é urgente manter um debate sobre o verdadeiro papel das tecnologias nas metodologias ativas, no sentido de desfazer o mito em que teorizam e atrelam o seu potencial ao uso das tecnologias na educação. Nesse estudo, o PBL se apresentou como uma metodologia que não depende de tecnologias mediadoras para ser aplicado, o que poderia indicar uma razão para ele ser utilizado na área de saúde, majoritariamente presencial, com muitas atividades práticas, mas normalmente sem a presença intensiva de TICs no desenvolvimento de seus cursos.

A Tabela 1 lista milhares de ocorrências para os termos "educação", "ensino" em trabalhos em português e "learning process" para o inglês. Percebe-se uma grande quantidade de "educational technology" e "distance education" em todos os idiomas e um uso mais restrito para educação ou ensino presencial em relação àquele a distância, já que a não adjetivação, via-de-regra, leva a estudos de cursos desenvolvidos presencialmente. Finalmente, os processos de "ensino-aprendizagem" também tiveram grande ocorrência nas publicações acadêmicas listadas no site pesquisado.

Tabela 1. Ocorrência de alguns termos relacionados à educação presencial e a distância obtida no “Google acadêmico” para os anos de 2015, 2016 e 2017.

\begin{tabular}{lcccccc}
\hline \multirow{2}{*}{ Termo de consulta } & \multicolumn{2}{c}{2015} & \multicolumn{2}{c}{2016} & \multicolumn{2}{c}{2017} \\
\cline { 2 - 7 } & Inglês & Português & Inglês & Português & Inglês & Português \\
\hline Learning Process & 88.000 & 3.120 & 84.100 & 3.680 & 71.900 & 3.190 \\
Educational Technology & 31.000 & 772 & 31.300 & 699 & 28.800 & 663 \\
Distance education & 16.900 & 1.210 & 17.700 & 1.300 & 20.000 & 850 \\
Educação & - & 125.000 & - & 124.000 & - & 109.000 \\
Educação a distância & - & 7.540 & - & 7.710 & - & 7.360 \\
Educação presencial & - & 859 & - & 838 & - & 653 \\
Ensino & - & 112.000 & - & 117.000 & - & 87.400 \\
Ensino a distância & - & 3.860 & - & 4.090 & - & 3.270 \\
Ensino presencial & - & 1.550 & - & 1.830 & - & 1.350 \\
Ensino-aprendizagem & - & 23.100 & - & 24.600 & - & 22.200 \\
\hline
\end{tabular}




\section{Considerações Finais}

Os pesquisadores que realizam trabalhos com metodologias ativas de aprendizagem nem sempre utilizam esse termo, preferindo registrar mais especificamente a metodologia utilizada, sem a referência de tratar-se de algo considerado ativo ou passivo por parte dos estudantes. Esse fato já foi detectado na área da saúde por Araújo (2013) que salienta, ainda, que os trabalhos não apresentam definições sobre metodologias ativas e que chama a atenção a fragilidade conceitual e teórica que parece estar presente nessa produção. ?

O EaD é um terreno muito fértil para o desenvolvimento de pesquisas voltadas para o uso e aplicação de metodologias ativas e inovadoras. Pelos resultados obtidos, entretanto, até o momento os relatos metodológicos em EaD não têm sido mais expressivo do que aqueles dos cursos presenciais, com uma proporção de trabalhos inferior à participação dessa modalidade no total de matriculados no ensino superior. Isso pode estar relacionado a vários fatores, dos quais destacamos a forte influência que tem a área de saúde, majoritariamente presencial, no cômputo final dessas publicações no Brasil e ainda, à quase exclusividade de desenvolvimento presencial dos programas de pós-graduação (mestrados e doutorados).

Finalmente, podemos especular que a oferta de cursos a distância ainda tem como principal preocupação a consolidação de sua qualidade frente aos cursos presenciais; que eles atendem a alunos de maior idade frente àqueles matriculados em cursos presenciais; e que, em muitos casos, limitam-se a reproduzir processos que já ocorrem em cursos desenvolvidos presencialmente, apenas adaptando suas estruturas ao desenvolvimento do aprendizado em espaços distintos, mas sem o uso intensivo de metodologias inovadoras. Tais inferências deverão fazer parte de novos trabalhos, a fim de que sejam checadas e contribuam para o entendimento da produção de conhecimento tratada na presente pesquisa.

\section{Referências}

Araujo, S.H.R. (2013) Análise de produção científica brasileira sobre as metodologias ativas de aprendizagem na área da saúde. Dissertação de Mestrado. Programa de Educação em saúde da Faculdade de Medicina da Universidade Federal de Alagoas, 43p.

Berbel, N.N. (1998). A problematização e a aprendizagem baseada em problemas: diferentes termos ou diferentes caminhos? Interface - Comunicação, Saúde, 
Educação, 2(2): 139-154.

BRASIL (1996). Lei de Diretrizes e Bases da Educação Nacional. Disponível em www.planalto.gov.br/Ccivil_03/leis/L9394.htm. Acessado em 10-04-2018.

CAPES/MEC (2016). Plataforma Sucupira: Classificação de Periódicos Quadriênio 2013-2016. Disponível em https://sucupira.capes.gov.br/sucupira/public/consultas/coleta/veiculoPublicacaoQualis/ listaConsultaGeralPeriodicos.jsf Acessado em 20-04/2018.

Fonseca, S.M. \& Mattar Neto, J.M. (2017). Metodologias ativas aplicadas à educação a distância: revisão de literatura. Revista EDaPECl - Educação a Distância e Práticas Educativas, Comunicacionais e Interculturais, 17(2): 185-197.

Google Acadêmico (2018). Disponível em: https://scholar.google.com.br/. Acessos desde outubro de 2017 e até abril de 2018.

INEP/MEC (2016) - Censo da Educação Superior. Disponível em http://portal.inep.gov.br/web/guest/sinopses-estatisticas-da-educacao-superior. Acessado em 10-04-2018.

Mattar J. (2017). Periódicos de EaD. Publicado em 22-10-2017. Disponível em http://joaomattar.com/blog/2017/10/22/periodicos-de-ead/. Acessado em 26-04-2018.

Morán, J. (2015). Mudando a educação com metodologias ativas. Disponível em http: //rh.unis.edu.br/wp-content/uploads/sites/67/2016/06/Mudando-a-Educacao-comMetodologias-Ativas.pdf. Acessado em 20-04-2018.

Rocha, E.F. (2014). Metodologias Ativas: um desafio além das quatro paredes da sala de aula. Disponível em: http://www.abed.org.br/arquivos/Metodologias_Ativas_alem _da_sala_de_aula_Enilton_Rocha.pdf. Acessado em 20-04-2018. 